REVIEW

\title{
Supratentorial cavernous haemangiomas and epilepsy: a review of the literature and case series
}

\author{
N F Moran, D R Fish, N Kitchen, S Shorvon, B E Kendall, J M Stevens
}

\begin{abstract}
Objectives-To characterise the clinical features and response to treatment of supratentorial cavernomas associated with epilepsy.

Methods-A systematic review of the literature was carried out and a retrospective case series of patients with cavernoma diagnosed by MRI and/or histology was compiled. Patient selection biases in the literature review were reduced as far as possible by selection of unbiased publications.

Results-In the literature, cavernomas were relatively less common in the frontal lobes. There were multiple cavernomas in $23 \%$ of cases. The main clinical manifestations were seizures $(79 \%)$ and haemorrhage $(16 \%)$. The annual haemorrhage rate was $0.7 \%$. The outcome after excision was good with improvement in seizures in $92 \%$ of patients. In the case series the surgical outcome was less favourable, reflecting inclusion of a higher proportion of patients with intractable epilepsy. In both the literature review and the case series, outcome was poorer in cases with a longer duration of seizures at the time of surgery. Conclusions-The good surgical results, particularly in cases treated earlier, and the significant cumulative haemorrhage rate, suggest that excision is the optimum treatment. However, these factors have not been examined prospectively and, despite the availability of several retrospective studies, the optimum treatment, particularly for non-intractable cases, will only be determined by a prospective study.

(F Neurol Neurosurg Psychiatry 1999;66:561-568)
\end{abstract}

Keywords: cavernous haemangioma epilepsy; magnetic resonance imaging; treatment; haemorrhage Dr N F Moran, The Epilepsy Research Group, The Institute of Neurology, 33 Queen Square, London WC1N 3BG, UK. email nmoran@ion.bpmf.ac.uk

Received 21 May 1998 and in revised form

28 December 1998

Accepted 14 January 1999 The cavernous haemangioma, or cavernoma, an increasingly recognised cause of partial epilepsy. Although there are several published series in this area, the optimum management remains uncertain, particularly the place of operative as opposed to conservative treatment. In cases of intractable epilepsy with good concordance of neuroimaging and other data, the indication for surgery is clear but there are no accepted guidelines for the management of patients with a recent onset or with nonintractable seizures.

The cavernoma is a benign, vascular lesion that may occur at any site within the CNS as well as other organs such as the liver or skin. Multiple lesions may occur, more commonly so in hereditary cases. ${ }^{12}$ Histologically, it consists of ectatic, endothelium lined channels without mural muscular or elastic fibres within a matrix of collagenous tissue lacking any neuronal elements. By contrast with arteriovenous malformations, cavernomas do not have a high pressure arterial supply or distinct venous drainage. At most, small feeding and draining vessels may be found. ${ }^{3}$ There may be non-specific features such as calcification or thrombosis. Typically, but not invariably, there is gliosis and haemosiderin deposition in the surrounding neural parenchyma. ${ }^{45}$

The aetiology of cavernomas is unknown. A minority of cases are hereditary with high penetrance, autosomal dominant transmission. ${ }^{67}$ The hereditary form is of high prevalence in Hispanic North Americans. ${ }^{8-11}$ Recently, an associated gene has been mapped to chromosome 7q11-q22 in Hispanic and white people, in some but not all families investigated. ${ }^{12-16}$ As cavernomas do not display any neoplastic features, they are widely assumed to be congenital although, other than rare reports of cavernomas occurring in utero or neonatally, ${ }^{17}{ }^{18}$ there is no direct evidence for this. On the other hand, there are reports of the de novo appearance of cavernomas and whereas this might be accounted for by non-mitotic lesion evolution, cellular multiplication has been directly observed in a cavernoma suggesting that postnatal development is a possibility. ${ }^{19}$ The prevalence of CNS cavernomas in the general population is unknown. The closest estimate is provided by postmortem studies, that disclose a frequency between 0.02 and $0.5 \% .^{2021}$

On T2 weighted MRI cavernomas typically 
Table 1 The anatomical location of cavernomas in 680 cases in the literature. As some cases had multiple lesions, there is a total of 690 locations

\begin{tabular}{lll}
\hline Location & $n$ & $\%$ \\
\hline Frontal lobe & 150 & 22 \\
Parietal lobe & 98 & 14 \\
Temporal lobe & 139 & 20 \\
Occipital lobe & 27 & 4 \\
Multilobar & 18 & 3 \\
Total lobar & 432 & 63 \\
Basal ganglia/thalamus & 27 & 4 \\
Supratentorial not specified & 93 & 13 \\
Total supratentorial & 552 & 80 \\
Brainstem & 95 & 14 \\
Cerebellum & 25 & 4 \\
Infratentorial not specified & 5 & 1 \\
Total infratentorial & 125 & 18 \\
Orbital & 2 & 0 \\
Spinal cord & 5 & 1 \\
Other† & 6 & 1 \\
Total & 690 & 100 \\
\hline
\end{tabular}

^Includes medulla oblongata, pons, mesencephalon, diencephalon, pineal gland, third ventricle, and fourth ventricle. tCorpus callosum, extradural, and lateral ventricle.

cases there may be contrast enhancement but this is not usually marked. After an acute bleed there may be a mass effect. ${ }^{22} 23$

\section{Methods}

LITERATURE REVIEW

Embase 1980-97 and Medline 1966-97 were searched using the term CAVERNOUS H?EMANGIOMA NOT CASE-REPORT limited to English language. This found 2411 references; a repeat of this search but substituting CAVERNOMA for CAVERNOUS H?EMANGIOMA did not yield any additional relevant articles. The title and abstract fields of these 2411 publications were examined to identify potentially relevant papers which were then obtained and assessed for suitability by one author (NFM). Papers were excluded for the following reasons: data on cavernomas and other lesions was combined such that data on cavernomas could not be extracted; data were confined to imaging characteristics; all cases were not confirmed by MRI or histology; family based studies; overlap with other included

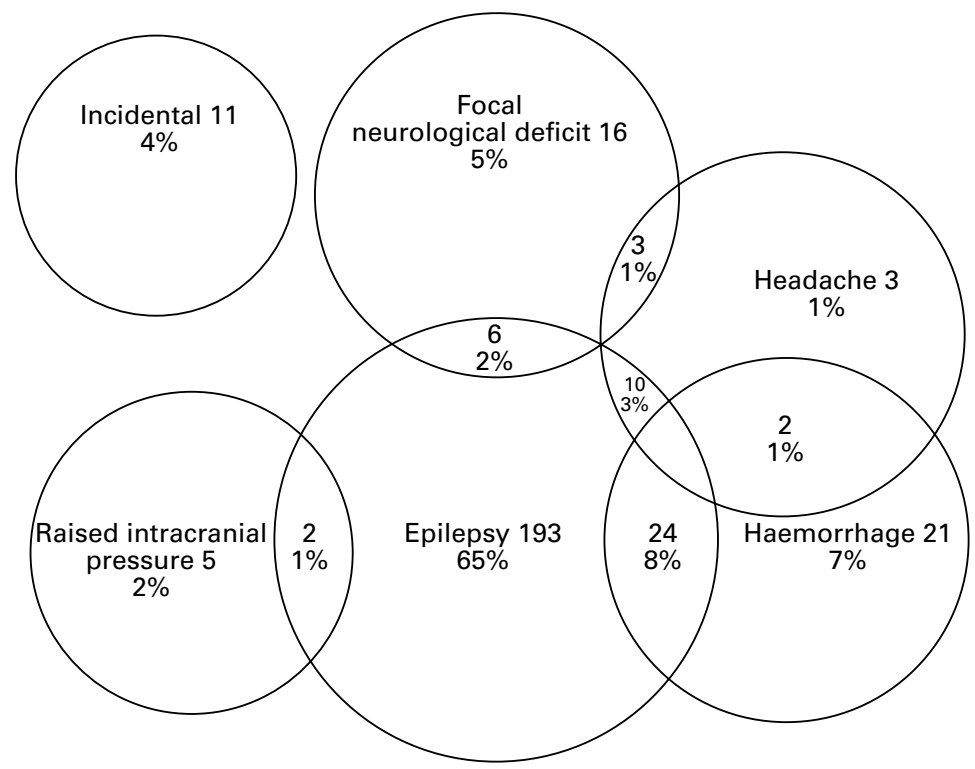

Figure 1 The clinical manifestations of 296 cases of supratentorial cavernomas in the literature review. series; the cases were not consecutive; the cases were selected according to their anatomical location (brainstem or deep seated hemispheric were excluded but series limited to supratentorial cavernomas were included). In addition, the reference lists of all papers obtained were examined. To estimate the sensitivity of the search, the two journals yielding the most papers, Acta Neurochirurgica (Wien) and fournal of Neurosurgery (eight and five respectively), were hand searched for a 10 year period from the beginning of 1987 . This resulted in only one further paper. Finally, 37 papers with 1222 cases were included. ${ }^{2}{ }^{23-57}$

Most series contained one or more biases with respect to case collection. Most prominently, $1122(92 \%)$ of cases were derived from neurosurgical centres. For each analysis below, papers were excluded if they contained a pertinent bias and, therefore, the number of subjects varies between different analyses.

\section{CASE SERIES}

Patients with cavernous haemangiomas were identified by searches of radiological and histopathological databases at The National Hospital for Neurology and Neurosurgery over the preceding 5 years. All MRI studies with reports suggestive of cavernoma were reexamined by two senior neuroradiologists (JMS and BEK). Cases were included if radiological appearances were typical or if there was a histological diagnosis of cavernous haemangioma. Clinical information was obtained by review of the case notes. Only patients with a history of seizures were included in the series reported here.

\section{Results}

ANATOMICAL LOCATION OF CAVERNOMAS

In the literature, after exclusion of series limited to supratentorial or infratentorial cavernomas or to only subjects with epilepsy (more likely to have supratentorial cavernomas), location was stated for 690 cavernomas in 680 patients. Five hundred and fifty two (80\%) were supratentorial and $125(18 \%)$ were infratentorial.

Further details of the anatomical distribution are shown in table 1 . In 308 patients in whom side was specified, 145 (47\%) cavernomas were right sided and 163 (53\%) were left sided; there was no significant difference in lesion laterality for any cerebral lobe.

\section{MULTIPLE CAVERNOMAS}

As MRI is the most sensitive investigation for detection of cavernomas, ${ }^{58}$ only series in which all cases were examined by MRI were included in this analysis. The prevalence of multiple cavernomas was thus analysed in 326 cases. Seventy five patients (23\%) had multiple cavernomas. Ten $(42 \%)$ were male and 14 $(56 \%)$ were female and sex was not stated in the remainder.

Based on 17 patients with multiple cavernoma in whom the number of cavernomas was stated, the mean per patient was 5.2 (range $2-19$, mode 3 ). In 44 patients for whom the data were available, there was no correlation 
Table 2 The occurrence of epilepsy in relation to cavernoma location in 261 cases. No significant differences were noted

\begin{tabular}{llllll}
\hline & \multicolumn{2}{l}{ No epilepsy } & & \multicolumn{2}{c}{ Epilepsy } \\
\cline { 2 - 3 } \cline { 5 - 6 } Site & $n$ & $\%$ & & $n$ & $\%$ \\
\hline Frontal lobe & 28 & 25 & & 49 & 33 \\
Parietal lobe & 37 & 33 & & 32 & 21 \\
Temporal lobe & 34 & 31 & & 51 & 34 \\
Occipital & 7 & 6 & & 9 & 6 \\
Multilobar & 5 & 5 & & 9 & 6 \\
Total & 111 & 100 & & 150 & 100
\end{tabular}

between the number of lesions and the age at which the subject was imaged (Pearson's $r$ 0.2). Although nine $(38 \%)$ patients with multiple lesions were Hispanic, race was specified in too few cases $(18,12 \%)$ to allow meaningful analysis. Similarly, anatomical location was only specified for 15 cavernomas.

Of 54 patients in whom the presence or absence of a family history was stated, there were 10 cases of multiple cavernomas, eight $(80 \%)$ of which were multiple. In the remaining 44 patients with solitary cavernomas, five $(11 \%)$ had a family history of cavernoma. Multiple cavernomas were thus clearly more frequent in the presence of a family history $\left(\chi^{2}=1 \times 10^{-5}\right)$.

In our series two patients had multiple cavernomas. Patient 10 had five (three cerebellar, one left parietal and one right orbitofrontal gyrus) and patient 6 had two closely associated lesions in the left superior temporal gyrus. Neither had a significant family history.

\section{CLINICAL MANIFESTATIONS (OVERVIEW)}

Literature review

For this analysis, series that did not state all manifestations in each case or that were biased with respect to manifestations (for example, those exclusive to patients with epilepsy even though other manifestations may also have been given) were excluded. Of 296 suitable cases, $235(79 \%)$ had seizures alone or in addition to other manifestations. Forty two $(18 \%)$ of those with epilepsy had additional manifestations, most commonly intracerebral haemorrhage in $24(10 \%)$ patients. The second commonest manifestation was intracerebral haemorrhage alone or with other manifesta-

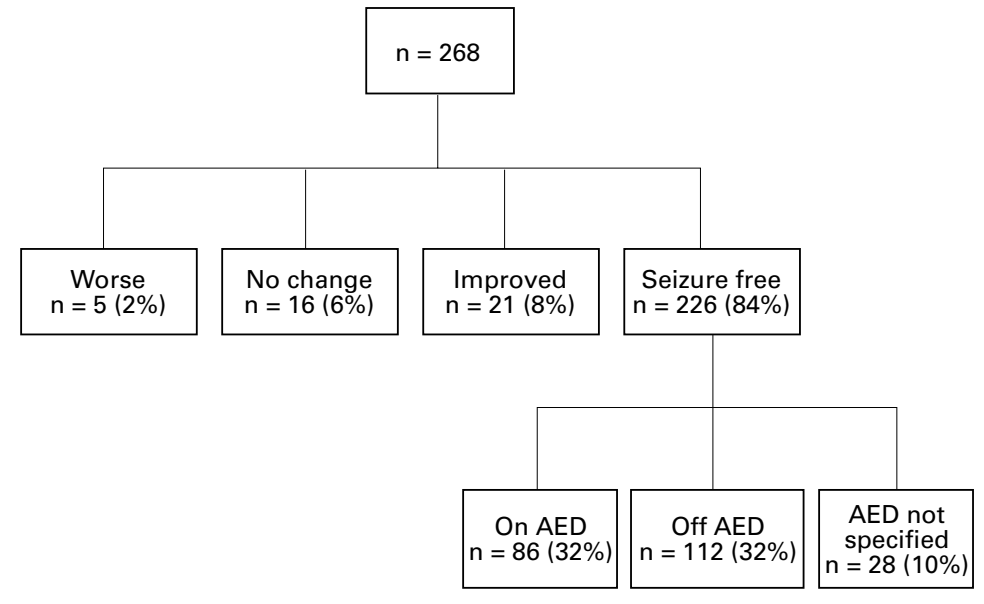

Figure 2 The outcome of surgery in 256 patients in the literature review with supratentorial cavernoma and seizure. AED=antiepileptic drug. tions, occurring in $47(16 \%)$ patients; sex was specified in only 23 of these cases (male 12, female 11). Further details of the clinical manifestations are illustrated in fig 1 .

\section{CASE SERIES}

By selection, all patients had seizures. In addition, there was a history of an acute neurological event in three $(9 \%)$ but with good evidence of an intracerebral haemorrhage in only one. Headache occurred in eight patients with migrainous features in two. Patient 31 had a mild right hemiparesis and patient 5 was noted to display right hyperreflexia. Patient 10 had multiple, biopsy confirmed capillary haemangiomas on the face and upper chest.

Prevalence of epilepsy in relation to lesion location in the literature

Only series in which all patients had MR examination were included as otherwise there may have been unrecognised multiple lesions. For lesions in the cerebral lobes, there were 261 patients in which lesion location and the presence or absence of epilepsy was stated. The relation between lesion site and epilepsy is shown in table 2. There were no significant associations of cavernoma site and the occurrence of seizures using $\chi^{2}$ tests.

\section{SEIZURE TYPES}

In the literature, seizure type was specified in 136 cases. Fifty eight $(43 \%)$ had secondary generalised seizures with or without other types; $50(37 \%)$ had complex partial with or without simple partial seizures; and $28(21 \%)$ had only simple partial seizures. No frontal lobe seizures or cases of status epilepticus were recognised. In our case series, $23(70 \%)$ patients had generalised seizures, although only a single one in five cases; 19 patients $(58 \%)$ had complex partial seizures.

The prevalence of generalised seizures in the literature was analysed according to the site of the cavernoma. After exclusion of cases with multiple lesions sufficient information was available in 110 cases (table 3 ). There was a higher proportion of generalised seizures for frontal lesions compared with all other sites $\left(\chi^{2}\right.$ test, $\mathrm{p}<0.001)$. Temporal lobe lesions were significantly less likely to be associated with generalised seizures compared with those in the other non-frontal sites $\left(\chi^{2}\right.$ test, $\left.p<0.001\right)$. In our case series, the findings were markedly different in that of 20 patients with temporal lobe lesions, $16(80 \%)$ had generalised seizures; of seven patients with frontal lobe cavernomas, two $(29 \%)$ had generalised seizures.

In 113 cases in the literature in which lesion location was specified, the presence or absence of intractable epilepsy was given. There was a tendency for temporal lobe cavernomas to be associated with intractable epilepsy but this was not significant $\left(\chi^{2}\right.$ test, $\left.\mathrm{p}<0.36\right)$. In our series, the proportion of intractable patients with temporal lobe lesions was similar to that with frontal lobe lesions $(56 \%$ and $57 \%$, respectively). 
Table 3 The occurrence of generalised seizures according to the site of the cavernomas in 110 cases from the literature

\begin{tabular}{|c|c|c|c|c|c|c|c|c|}
\hline \multirow{2}{*}{$\begin{array}{l}\text { Generalised } \\
\text { seizures }\end{array}$} & \multicolumn{2}{|c|}{ Frontal } & \multicolumn{2}{|c|}{ Parietal } & \multicolumn{2}{|c|}{ Temporal } & \multicolumn{2}{|c|}{ Occipital } \\
\hline & $n$ & $\%$ & $n$ & $\%$ & $n$ & $\%$ & $n$ & $\%$ \\
\hline+ & 30 & 79 & 9 & 39 & 8 & 21 & 5 & 56 \\
\hline- & 8 & 21 & 14 & 61 & 32 & 84 & 4 & 44 \\
\hline
\end{tabular}

Table 4 Seizure outcome according to cavernoma location from 109 cases in the literature. The number and percentage of patients seizure free after operation for each site is shown.

\begin{tabular}{llllll}
\hline \multirow{2}{*}{ Site } & \multicolumn{2}{l}{ Seizure free } & & \multicolumn{2}{c}{ Not seizure free } \\
\cline { 2 - 3 } \cline { 5 - 6 } \cline { 5 - 6 } & $N$ & $\%$ & & $N$ & $\%$ \\
\hline Frontal lobe & 46 & 88 & & 6 & 12 \\
Multilobar & 9 & 75 & & 3 & 25 \\
Occipital lobe & 9 & 100 & & 0 & 0 \\
Parietal lobe & 29 & 78 & & 8 & 22 \\
Temporal lobe & 35 & 90 & & 4 & 10 \\
Total & 128 & 86 & & 21 & 14 \\
\hline
\end{tabular}

None of the differences reached significance.

\section{TREATMENT AND OUTCOME IN EPILEPSY \\ Literature review}

Four hundred and three patients with seizures were operated on. The mean age at surgery was 33 years. Further analysis was restricted to 268 cases in which at least 12 months postoperative follow up was given. We adopted a simplified version of Engel's classification ${ }^{59}$ system to accommodate the outcome data available in the literature, placing cases in the categories seizure free, improved, no change, or worse.

Of the 268 cases analysed, 226 (84\%) were seizure free and $21(8 \%)$ were improved; in 16 cases $(6 \%)$ there was no change and in five
(2\%) there was deterioration (fig 2). No postoperative deaths were reported in the series analysed, although they have been reported in other patients undergoing epilepsy surgery for cavernomas. $^{35}$

In 85 patients in the literature in whom individual data were available, the duration of seizures at the time of operation was significantly shorter in the group with a seizure free outcome compared with the group with continuing seizures: mean 3.5 years (SD 4.5), range $0.0-19.0$ and mean 8.2 years (SD 7.0), range $0.0-23$, respectively (two tailed $t$ test, $\mathrm{p}<0.002)$. The mean age of onset of seizures was greater in the seizure free group than in the group with continuing seizures but this was not significant: mean 24.5 years (SD 15.5, range $0.25-63.5$ and 18.6 years (SD 9.2), range 1.93.6 , respectively (two tailed $t$ test, $\mathrm{p}=0.16$ ). The breakdown of seizure outcome in the literature in relation to cavernoma location is shown in table 4 . On $\chi^{2}$ testing none of the differences were significant.

CASE SERIES

The individual clinical details are presented in detail in table 5. Seventeen patients were operated on. In two patients two operations were performed. The operation type was lesionectomy in 14 cases (82\%) (with stereotactic guidance in eight), temporal lobectomy in one, electrocorticographically guided frontal lobectomy in one, and subpial transection in one. The mean age at surgery (second operation where relevant) was 37.3 years (SD 8.5), range 27-54. In one (patient 23), the lesion remained

Table 5 Patient details and postoperative outcome. For outcome rating scale see Vickrey et al ${ }^{59}$

\begin{tabular}{|c|c|c|c|c|c|c|c|}
\hline $\begin{array}{l}\text { No/sex/onset } \\
(y)\end{array}$ & Locn & Operation & Seizure type & $E E G$ & Histology & Follow upt & $\begin{array}{l}\text { Surgical } \\
\text { outcome }\end{array}$ \\
\hline $1 / \mathrm{F} / 17^{\star}$ & rt tl & - & CP, 2GTC, SE & V: multifocal onset, rt and lt temporal & ND & 13 & - \\
\hline $2 / \mathrm{M} / 53$ & rt fl & - & FM & R: N & ND & 1.5 & - \\
\hline $3 / F / 15$ & lt tl & - & $\mathrm{CP}, 2 \mathrm{GTC}$ & R: lt temporal slow & ND & 10 & - \\
\hline $4 / \mathrm{M} / 10^{\star}$ & rt fl & - & $\mathrm{FM}$ & $\mathrm{R}: \mathrm{nf}$ & ND & 17 & - \\
\hline $5 / \mathrm{M} / 45$ & rt pl & - & 2GTC & $\mathrm{R}: \mathrm{nf}$ & ND & 1.5 & - \\
\hline $6 / \mathrm{M} / 21$ & $\mathrm{~m}$ & - & $\mathrm{CP}$ & $\mathrm{R}:$ lt midanterior temporal sharp and slow & ND & 15 & - \\
\hline $7 / \mathrm{M} / 25$ & rt fl & - & 2GTC & $\mathrm{R}: \mathrm{N}$ & ND & 5 & - \\
\hline $8 / \mathrm{M} / 43$ & rt tl & - & $\mathrm{CP}, 2 \mathrm{GTC}$ & $\mathrm{R}: \mathrm{nf}$ & ND & 20 & - \\
\hline 9/F/41 & rt tl & - & $\mathrm{CP}, 2 \mathrm{GTC}$ & $\mathrm{R}: \mathrm{nf}$ & ND & 3 & - \\
\hline $10 / \mathrm{M} / 57$ & $\mathrm{~m}$ & - & FL & $\mathrm{R}: \mathrm{N}$ & ND & 3 & - \\
\hline $11 / \mathrm{F} / 23$ & rt tl & - & $\mathrm{CP}, 2 \mathrm{GTC}$ for $17 \mathrm{y}$ & $\mathrm{R}$ : $\mathrm{rt}$ ant temporal sharp waves & ND & 25 & - \\
\hline $12 / \mathrm{M} / 20$ & lt tl & - & $\mathrm{CP}, 2 \mathrm{GTC}$ & $\mathrm{R}: \mathrm{N}$ & ND & 3 & - \\
\hline $13 / \mathrm{M} / 11^{\star}$ & rt tl & - & FL & V: not localising or lateralising & ND & 37 & - \\
\hline $14 / \mathrm{F} / 16$ & lt tl & - & $\mathrm{CP}, 2 \mathrm{GTC}$ & $\mathrm{R}$ : onset lt temporal & ND & 14 & - \\
\hline $15 / \mathrm{F} / 49$ & $\mathrm{rt} \mathrm{fl}$ & - & $\mathrm{CP}$ & NA & ND & 0.5 & - \\
\hline $16 / F / 34$ & rt pl & - & 2GTC & $\mathrm{R}: \mathrm{N}$ & ND & 8 & - \\
\hline $17 / \mathrm{F} / 12^{\star}$ & lt tl & $50 / \mathrm{Lx}$ & SP, 2GTC & R: bitemporal spikes lt $>r t$ & + & 4.5 & IV (2) \\
\hline $18 / \mathrm{F} / 23^{\star}$ & rt fl & $35 / \mathrm{Fx}$ & $\mathrm{CP}, 2 \mathrm{GTC}$ & $\mathrm{V}$ : onset rt frontal & + & 1 & IV (2) \\
\hline $19 / \mathrm{F} / 19^{\star}$ & lt tl & $29 / \mathrm{Lx}$ & SP, CP, 2GTC & V: interict spikes lt frontal; no seizures; & + & 2 & IV (1) \\
\hline $20 / M / 45$ & rt tl & $46 / \mathrm{Lx}$ & SP, 2GTC & NA & + & 1 & I (1) \\
\hline $21 / \mathrm{F} / 15^{\star}$ & $\mathrm{rt} \mathrm{tl}$ & $40 / \mathrm{Lx}$ & $\mathrm{SP}, \mathrm{CP}$ & $\mathrm{V}$ : onset $\mathrm{rt} \mathrm{h} / \mathrm{s}$ & + & 8 & I (2) \\
\hline $22 / \mathrm{F} / 35$ & rt tl & $35 / \mathrm{Lx}$ & 2GTC & NA & + & 1 & I (1) \\
\hline $23 / \mathrm{M} / 16^{\star}$ & lt tl & $30 / \mathrm{Lx}(\mathrm{x} 2)$ & CP, 2GT, 2GTC & R: nf & + & 2 & III (1) \\
\hline $24 / \mathrm{M} / 20^{\star}$ & lt $\mathrm{fl}$ & $48 / \mathrm{Lx}$ & FL & V: not localising or lateralising & + & 4 & III (1) \\
\hline $25 / M / 28$ & lt tl & $32 / \mathrm{Lx}$ & $\mathrm{CP}, 2 \mathrm{GTC}$ & $\mathrm{R}:$ lt frontotemporal spikes & + & 2 & I (1) \\
\hline $26 / \mathrm{M} / 11^{\star}$ & lt tl & $29 / \mathrm{Lx} / \mathrm{TLx}$ & $\mathrm{CP}, 2 \mathrm{GTC}$ & $\mathrm{V}:$ lt $\mathrm{h} / \mathrm{s}$ onset & + & 7 & III (1) \\
\hline $27 / \mathrm{M} / 24^{\star}$ & rt tl & $37 / \mathrm{Lx}$ & CP, GTC & V: not localising or lateralising & + & 4 & I (3) \\
\hline $28 / \mathrm{F} / 30^{\star}$ & rt tl & $47 / \mathrm{Lx}$ & $\mathrm{CP}, 2 \mathrm{GTC}$ & V: onset rt temporal & + & 4 & II $(2)$ \\
\hline $29 / \mathrm{M} / 1.5^{\star}$ & rt tl & $27 / \mathrm{Lx}$ & $\mathrm{CP}$ & $\mathrm{V}$ : interict $\mathrm{rt}$ temporal sharp and slow; onset $\mathrm{rt} \mathrm{h} / \mathrm{s}$ & + & 2.5 & I (1) \\
\hline $30 / \mathrm{M} / 50^{\star}$ & rt ol & $54 / \mathrm{Lx}$ & $\mathrm{CP}, 2 \mathrm{GTC}$ & V: nf; no seizures & + & 4 & II (2) \\
\hline $31 / \mathrm{F} / 19$ & lt $\mathrm{pl}$ & $30 / \mathrm{Lx}$ & $\mathrm{SP}$ & $\mathrm{V}: \mathrm{N}$; no seizures & + & 1 & IV (2) \\
\hline $32 / \mathrm{F} / 28$ & lt ol & $29 / \mathrm{Lx}$ & SP, 2GTC & R: N & + & 3 & II (2) \\
\hline $33 / \mathrm{F} / 21^{\star}$ & rt fl & $33 / \mathrm{spt}$ & SP, 2GTC & $\mathrm{R}$ : rt frontotemporal multifocal sharp and slow & nd & 6 & II (3) \\
\hline
\end{tabular}

$2 \mathrm{GTC}=$ secondarily generalised tonic clonic seizure; $\mathrm{CP}=$ complex partial seizure; $\mathrm{f}=$ frontal lobe; $\mathrm{FL}=$ frontal lobe seizure; $\mathrm{Fx}=$ frontal lobe resection; $\mathrm{FM}=$ focal motor seizure; $\mathrm{h} / \mathrm{s}=$ hemisphere; $1 \mathrm{t}=\mathrm{left} ; \mathrm{Lx}=$ lesionectomy; $\mathrm{m}=$ normal; $\mathrm{NA}=$ not available; $\mathrm{ND}=$ not done; nf=no focal, regional or lateralising abnormality; ol=occipital lobe; $\mathrm{pl}=$ parietal lobe; $\mathrm{rt}=$ right; $\mathrm{R}=$ routine scalp $\mathrm{EEG}$; $\mathrm{SE}=$ status epilepticus; $\mathrm{SP}=$ simple partial seizure; spt=subpial transection; tl=temporal lobe; $\mathrm{V}=$ video $\mathrm{EEG}$;

†Non-operated patients: time from onset to last follow up; operated patients: time from operation to last follow-up

*Medically intractable. 


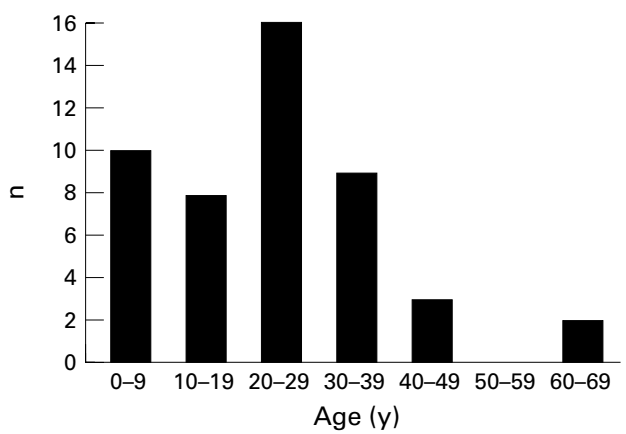

Figure 3 Age of first haemorrhage in 47 cases in the literature review.

after attempted stereotactic lesionectomy and therefore a repeat lesionectomy was performed 7 months later. In the second (patient 26) there was no improvement in epilepsy after stereotactic lesionectomy and, although the lesion had been removed, a temporal lobectomy was performed 4 years later.

The mean postoperative follow up was 3.2 years (SD 2.1), range 0.73-8.3. The outcome in six patients $(35 \%)$ fell into Engel's class I-that is, seizure free; four $(24 \%)$ were class II - that is, rare seizures; three $(18 \%)$ were class III-that is, worthwhile improvement; the remaining four $(24 \%)$ were class IV - that is, no worthwhile improvement. In no patients was there any deterioration in preoperative focal neurological deficits. Patient 19 developed postoperative non-convulsive status epilepticus and subsequently exhibited expressive dysphasia that had largely resolved at a 6 month follow up. The duration of epilepsy at the time of operation was greater in patients with class IV outcome (mean 21 years (SD 12), range 12-38) than in those with class I-III outcome (mean 12 years (SD 10), range 0.7-28) but this was not significant.

\section{HAEMORRHAGE RATE}

In 47 cases in the literature the age of haemorrhage was specified (fig 3). The mean age of haemorrhage was 23.5 years (median 20.2 (SD 15.2), range 0.6-63.5). To estimate the haemorrhage rate, cases were identified in which the first manifestation was not a haemorrhage and data were given on the subsequent clinical course, including the duration of follow up from the initial manifestation. For each case, the length of observation was considered to be the interval between the first manifestation and the last available follow up or excision. In 145 patients sufficient data were available for inclusion in this analysis. The mean follow up period was 5.6 years (median 4.6 years, (SD 5.8), range $0.01-24.5 ; 17 \%$ of those remaining at risk at 5 years and $13 \%$ at 10 years) and the total person-years of observation was 810 . Six $(4 \%)$ had a haemorrhage subsequent to their initial manifestation giving a probability rate for haemorrhage of $7 \times 10^{-3}(0.7 \%$ / year $)$.

\section{Discussion}

There is an overrepresentation of operated cases in the literature partly because before the widespread availability of MRI the diagnosis of cavernoma could not be confidently made without histological examination; MRI is the most sensitive and specific non-invasive investigation in the diagnosis of the cavernous haemangioma and allows the diagnosis to be made with sufficient confidence to allow comparison of conservatively and surgically treated cases. $^{22} 23$

We have therefore carried out a literature review and retrospective case series of patients with epilepsy associated with supratentorial cavernomas, minimising selection bias by inclusion of cases diagnosed by MRI alone as well as by histological examination with or without MRI. As the MRI appearances of the cavernous haemangioma are not entirely specific, the study may include a few false positive cases reducing its internal validity. Nevertheless, this reflects clinical practice and is therefore likely to be more valuable in the development of guidelines for management.

In the literature review cavernomas were distributed above $(80 \%)$ and below $(18 \%)$ the tentorium, which is roughly in proportion to the volume of brain in these areas. In both the literature review and the current series, relative to brain volume, cavernomas occurred less often in the frontal lobes than in the other cerebral lobes. This may reflect a higher proportion of frontal lesions remaining asymptomatic due to their location in "silent" cortical areas, rather than a true preponderance of cavernomas in non-frontal sites. There was an excess of temporal lobe lesions in the case series possibly resulting from a case selection bias toward intractable epilepsy. It has been suggested that temporal lobe cavernomas are more likely to be associated with intractability ${ }^{28}$ and this trend was evident in the literature review although it did not reach significance. The excess of left frontal over right frontal lesions in the case series was likely to be chance as the numbers were small and were not confirmed by the literature review.

Previous estimates of the prevalence of multiple cavernomas have varied widely, and have been as high as $50 \% .^{22}$ Many estimates are likely to be inaccurate due to inclusion of those not examined by MRI, overrepresentation of Hispanic people and case finding by formal or informal recruitment of probands' relatives. With respect to the prevalence of multiple lesions, our literature review considered only series in which all subjects received MRI, but eliminating the last two biases was impossible as few papers explicitly declare them. We therefore think that our estimated multiple lesion prevalence of $23 \%$ is the most accurate possible, but the true prevalence may well be lower as reflected by the 3\% prevalence in our series which excluded the above biases, although the sample is small. It has been suggested that multiple lesions are more common in females ${ }^{60}$ but this was not supported by the literature review.

The literature review did not suggest that cavernomas in the temporal lobe are more likely to be associated with seizures than the other sites. In the literature review, $43 \%$ of patients experienced generalised seizures com- 
pared with $70 \%$ in the series. This is likely to reflect a selection bias toward more intractable patients in the second. In the literature, frontal lobe cavernomas were more often associated with generalised seizures and temporal lobe cavernomas less often. It seems likely that a proportion of the seizures associated with frontal lobe cavernomas were in fact frontal lobe seizures.

For supratentorial cavernomas, our review provides the largest survey of the clinical manifestations. A high proportion of patients, $79 \%$, experienced seizures underlining the increasing importance of these lesions in epilepsy practice. It is likely that before the widespread availability of MRI many cases of epilepsy associated with cavernomas remained cryptogenic.

The seizure outcome of lesionectomy in the literature seems excellent with improvement in seizure control in $92 \%$ of cases, amounting to abolishment of seizures in $84 \%$. However, this should be interpreted bearing in mind the limitations of the data available in the literature. The detail with which outcome was described was scant in many papers and very few used a recognised rating scale. We therefore adopted a simplified version of Engel's classification system $^{59}$ to accommodate the outcome data available, placing cases in the categories seizure free, improved, no change, or worse. Patients reported to be seizure free without any further qualification or with some qualification, such as auras only, compatible with Engel's category I were placed in the seizure free category. These broad categories will, in reality, encompass a wide range of outcomes. There have been no prospective trials with patients randomised to conservative or operative treatment. Retrospective series will contain significant bias towards subjects with characteristics that are favourable for good outcome after surgery. Although most of these patients did well after surgery, many of them may have done equally as well with medical treatment alone.

The seizure outcome in our case series was less favourable than in the literature review, probably reflecting the high proportion of intractable patients. This underlines the need to consider the results of seizure outcome in the literature critically and consider individual patient factors in detail. Three (patients 17, 18, and 26) of the four patients falling into class IV (no appreciable change) had EEG data suggestive of additional seizure foci outside the operated area. In the fourth ${ }^{33}$ the location of the lesion in the precentral gyrus limited surgery to a subpial transection. In our series, the mean duration of epilepsy at the time of operation in the class IV patients was longer than those with better outcome. This finding was confirmed by the literature review. Similar findings have been reported for arteriovenous malformations. ${ }^{61}$ According to Morrell's model of secondary epileptogenesis, increased duration of epilepsy favours the evolution of secondary epileptogenic foci remote from the structural lesion. ${ }^{62}$ If, as these findings suggest, the duration of epilepsy at the time of surgery has a negative influence on seizure outcome, then there is a case for performing resection sooner rather than later. However, in retrospective studies such as the present one, it is not possible to draw firm conclusions regarding these factors.

It was only possible to analyse the outcome of lesionectomy as there are very few reported cases in which other forms of surgery, particularly temporal lobectomy, were employed. The increasing recognition of dual pathology (a temporal lobe lesion in addition to mesial temporal sclerosis), ${ }^{63}$ however, makes this an area in need of further investigation. In one of the patients in our case series (patient 26) an initial lesionectomy provided no improvement but there was worthwhile improvement after subsequent anterior temporal lobectomy that included the mesial temporal lobe structures. Unfortunately, because of tissue fragmentation it was not possible to determine whether or not this patient had mesial temporal histological abnormalities. The good outcome figures may suggest that excision should be performed whenever technically feasible.

The second commonest manifestation of cavernous haemangiomas in the literature review was intracerebral haemorrhage. The definition of haemorrhage is confused in the literature as some authors include cases with histological evidence of haemorrhage but without a suggestive clinical history. To what extent clinical manifestations arise from non-dramatic bleeds is unclear, but in our analyses we have restricted the definition of haemorrhage to mean a typical clinical intracranial haemorrhage event or a less typical event, such as headache or a seizure, with clear radiological evidence of an acute bleed. We have estimated the risk of haemorrhage to be $0.7 \%$ a year. For this analysis, we excluded patients who had first presented with a haemorrhage and defined the beginning of the observation time as the onset of the first manifestation which was usually epilepsy or seizures. Ideally, the estimation of haemorrhage risk would be derived from an unselected group of patients with cavernomas identified by a screening process. In the absence of these data, however, we think that our approach offers the most accurate and clinically useful estimation of haemorrhage risk. It may overestimate the risk as individuals with no manifestations subsequent to their initial one are probably more likely to be lost to follow up. Previous authors have estimated haemorrhage rate in cavernomas (supratentorial and infratentorial) to lie between $0.25 \%$ and $1.3 \%$ a year. ${ }^{20} 3946$ The higher estimates probably result from inclusion of patients who had previous bleeds as in such cases repeat haemorrhage is more likely; Kondziolka et al, for example, found that the risk of a repeat haemorrhage was 7.5 times greater than the risk of a first haemorrhage. ${ }^{46}$

As the number of patients with long follow up in the literature was limited we have not presented an actuarial analysis of haemorrhage rate. However, fig 3 illustrates the age of occurrence of all haemorrhages in the literature, regardless of whether haemorrhage was the initial manifestation or if this was not stated. Ninety per cent of haemorrhages occurred 
below the age of 40 years, with a peak in the third decade, suggesting that the risk of haemorrhage is not constant at different ages. It should be stressed that this discussion is restricted to supratentorial cavernomas. Those in the infratentorial compartment require separate consideration. ${ }^{64}$

The effect, if any, of pregnancy on the behaviour of cavernomas and their associated symptoms, is unknown. Whereas there are reports of haemorrhage and new onset of epilepsy during pregnancy ${ }^{65-67}$ we think that it is impossible to determine whether there is an association from the literature as no case series report the proportion of patients who were not pregnant at the time of a bleed. In the literature review, there was no excess of females with haemorrhage which might be expected if pregnancy is a major factor.

Experience with radiosurgery in the treatment of cerebral cavernomas is greatest in the prevention of haemorrhage from brainstem lesions. Whereas some authors have reported good results others have found a high rebleed rate $(8-33 \%)$ with a high incidence of radiation induced complications and a histological study failed to find any significant changes in cavernoma tissue post-irradiation. ${ }^{68-73}$ There are very little data on the effect of irradiation on epilepsy. At least until further data are available, radiosurgery should be reserved for cases in which haemorrhage has already occurred and the lesion is judged to be inoperable.

\section{Conclusion}

The lack of prospective studies limits the development of optimum clinical management of epilepsy associated with cavernoma. Retrospective surgical series may often show good results with a high proportion of patients seizure free or improved after surgery, but the outcome in such patients if they had not undergone surgery is unknown. In cases of medically intractable epilepsy in which operation is technically feasible and it can be shown that at least a high proportion of the seizures can be localised to the region of the cavernoma, surgery is a reasonable option. However, in non-intractable cases it is unclear whether early surgery is advantageous. It is plausible that a longer duration of epilepsy may prejudice the outcome of any surgery ultimately performed. Kindling effects may play a part in increasing intractability but in addition, although the cavernoma is a benign lesion, it is an evolving one subject to repeated or possibly continuous haemorrhage and reactive organisation with the potential to produce disruption of surrounding tissue and the deposition of haemosiderin known to be potently epileptogenic. ${ }^{74}$ Serial MRI may offer a useful means of following lesion evolution for this purpose. A more complete understanding of the biological behaviour of the cavernoma and the relation of this to epileptogenesis may contribute to the development of more rational management but ultimately the question of the optimum management of the cavernoma presenting with epilepsy can only be addressed by a prospective trial with randomisation to operative and non- operative treatment. Based on our experience and other published retrospective series, such a clinical trial would be feasible with a multicentre approach.

NM is funded by The Patrick Berthoud Fellowship.

1 Perlemuter G, Benjanin H, Fritsch J, et al. Biliary bstruction caused by portal cavernoma: a study of 8 cases. Hepatol 1996;25:58-63.

2 Giombini S, Morello G. Cavernous angiomas of the brain. Account of 14 personal cases and review of the literature. Acta Neurochir Wien 1978;40:61-82.

3 Simard JM, Garcia Bengochea F, Ballinger WE Jr, et al. Cavernous angioma: a review of 126 collected and 12 new clinical cases. Neurosurgery 1986;18:162-72.

4 Bigger DD, McLendon RE, Bruner JM, eds. Russell and Rubinstein's pathology of tumours of the nervous system. 6th ed. London: Arnold, 1989:730-6.

5 McCormick WF. The pathology of vascular (arteriovenous) malformations. I Neurosurg 1966;24:807-16.

6 Hayman LA, Evans RA, Ferrell RE, et al. Familial cavernous angiomas: natural history and genetic study over a 5-year period. Am f Med Genet 1982:11:147-60.

7 Bicknell JM, Carlow TJ, Kornfeld M, et al. Familial cavernous angiomas. Arch Neurol 1978;35:746-9.

8 Zabramski JM, Wascher TM, Spetzler RF, et al. The natural history of familial cavernous malformations: results of an ongoing study. F Neurosurg 1994;80:422-32.

9 Rigamonti D, Hadley MN, Drayer BP, et al. Cerebral cavernous malformations. N Engl f Med 1988;319:343-7.

10 Kattapong VJ, Hart BL, Davis LE. Familial cerebral cavernous angiomas: clinical and radiologic studies. Neurology 1995;45:492-7.

11 Mason I, Aase JM, Orrison WW. Familial cavernous angiomas of the brain in an Hispanic family. Neurology 1988;38:324-6.

12 Dubovsky J, Zabramski JM, Kurth J, et al. A gene responsible for cavernous malformations of the brain maps to chromosome 7q. Hum Mol Genet 1995;4:453-8.

13 Gil Nagel A, Dubovsky J, Wilcox KJ, et al. Familial cerebral cavernous angioma: a gene localized to a 15-cM interval on cavernous angioma: a gene localized to a 15-cM
chromosome 7q. Ann Neurol 1996;39:807-10.

14 Gunel M, Awad IA, Anson J, et al. Mapping a gene causing cerebral cavernous malformation to $7 \mathrm{q} 11.2-\mathrm{q} 21$. Proc Natl cerebral cavernous malformation

15 Marchuk DA, Gallione CJ, Morrison LA, et al. A locus for cerebral cavernous malformations maps to chromosome $7 \mathrm{q}$ in two families. Genomics 1995;28:311-14.

16 Johnson EW, Iyer LM, Rich SS, et al. Refined localization of the cerebral cavernous malformation gene (CCM1) to a 4-cM interval of chromosome $7 \mathrm{q}$ contained in a welldefined YAC contig. Genome Res 1995;5:368-80.

17 Moritake K, Handa H, Nozaki K, et al. Tentorial cavernous angioma with calcification in a neonate. Neurosurgery 1985 ; 16:207-11.

18 Sabatier J, Gigaud M, Dubois G, et al. Cavernoma in the child. Apropos of a neonatal form with recurrence in childhood. Neurochirurgie 1989;35:109-10.

19 Pozzati E, Giuliani G, Nuzzo G, et al. The growth of cerebral cavernous angiomas. Neurosurgery 1989;25:92-7.

20 Robinson JR, Awad IA, Little JR. Natural history of the cavernous angioma. $\mathcal{F}$ Neurosurg 1991;75:709-14.

21 Otten P, Pizzolato GP, Rilliet B, et al. 131 cases of cavernous angioma (cavernomas) of the CNS, discovered by retrospective analysis of 24535 autopsies. Neurochirurgie 1989; 35:128-31

22 Rigamonti D, Drayer BP, Johnson PC, et al. The MRI appearance of cavernous malformations (angiomas). $f$ Neurosurg 1987;67:518-24.

23 Sage MR, Brophy BP, Sweeney C, et al. Cavernous haemangiomas (angiomas) of the brain: clinically significant lesions. Australas Radiol 1993;37:147-55.

24 Ferrante L, Palma L, d'Addetta R, et al. Intracranial cavernous angioma. Neurosurg Rev 1992;15:125-33.

25 Tagle P, Huete I, Mendez J, et al. Intracranial cavernous angioma: presentation and management. $\mathcal{F}$ Neurosurg 1986 ; 64:720-3.

26 Yamasaki T, Handa $\mathrm{H}$, Yamashita J, et al. Intracranial and orbital cavernous angiomas. A review of 30 cases. 7 Neuroorbital cavernous angio
surg 1986;64:197-208.

27 Zevgaridis D, van Velthoven V, Ebeling U, et al. Seizure control following surgery in supratentorial cavernous malformations: a retrospective study in 77 patients. Acta Neurochir Wien 1996;138:672-7.

28 Casazza M, Broggi G, Franzini A, et al. Supratentorial cavernous angiomas and epileptic seizures: preoperative course and postoperative outcome. Neurosurgery 1996;39: 26-32.

29 Ryvlin P, Mauguiere F, Sindou M, et al. Interictal cerebral metabolism and epilepsy in cavernous angiomas. Brain 1995;118:677-87.

30 Lunardi P, Acqui $M$. The echo-guided removal of cerebral cavernous angiomas. Acta Neurochir Wien 1993;123:11317.

31 Churchyard A, Khangure M, Grainger K. Cerebral cavernous angioma: a potentially benign condition? Successful
treatment in 16 cases. F Neurol Neurosurg Psychiatry 1992;55:1040-5.

32 Vaquero J, Salazar J, Martinez R, et al. Cavernomas of the central nervous system: clinical syndromes, CT scan diag- 
nosis, and prognosis after surgical treatment in 25 cases. Acta Neurochir Wien 1987:85:29-33.

33 Steiger HJ, Markwalder TM, Reulen HJ. Clinicopathological relations of cerebral cavernous angiomas: observations in eleven cases. Neurosurgery 1987;21:879-84.

34 Di Rocco C, Iannelli A, Tamburrini G. Cavernomas of the central nervous system in children. A report of 22 cases. Acta Neurochir Wien 1996;138:1267-74.

35 Cohen DS, Zubay GP, Goodman RR. Seizure outcome after lesionectomy for cavernous malformations. 7 Neurosurg 1995;83:237-42.

36 Aiba T, Tanaka R, Koike T, et al. Natural history of intracranial cavernous malformations. f Neurosurg 1995;83:56-9.

37 Tomlinson FH, Houser OW, Scheithauer BW, et al. Angiographically occult vascular malformations: a correlative study of features on magnetic resonance imaging and histological examination. Neurosurgery 1994;34:792-9.

38 Scott RM, Barnes P, Kupsky W, et al. Cavernous angiomas of the central nervous system in children. $f$ Neurosurg 1992;76:38-46.

39 Del Curling O Jr, Kelly DL Jr, Elster AD, et al. An analysis of the natural history of cavernous angiomas. $f$ Neurosurg of the natural hist

40 Villani RM, Arienta C, Caroli M. Cavernous angiomas of the central nervous system. F Neurosurg Sci 1989;33:22952.

41 Frima Verhoeven PA, Op de Coul AA, Tijssen CC, et al. Intracranial cavernous angiomas: diagnosis and therapy. Eur Neurol 1989;29:56-60.

42 Farmer JP, Cosgrove GR, Villemure JG, et al. Intracerebral cavernous angiomas. Neurology 1988;38:1699-704.

43 Herter T, Brandt M, Szüwart U. Cavernous hemangiomas in children. Childs Nerv Syst 1988;4:123-7.

44 Buckingham MJ, Crone KR, Ball WS, et al. Management of cerebral cavernous angiomas in children presenting with seizures. Childs Nerv Syst 1989;5:347-9.

45 Cappabianca P, Alfieri A, Maiuri F, et al. Supratentorial cavernous malformations and epilepsy: seizure outcome after ernous malformations and epilepsy: seizure outcome after lesionectomy on a series
surg 1997;99:179-83.

46 Kondziolka D, Lunsford LD, Kestle JR. The natural history of cerebral cavernous malformations. $\mathcal{f}$ Neurosurg $1995 ; 83$ : $820-4$.

47 Salanova V, Markand ON, Worth R. Cavernous angiomas and refractory temporal lobe epilepsy: excellent results following lesionectomy and removal of the epileptogenic zone, sparing the mesial temporal structures. Fournal of Epilepsy 1994;7:52-6.

48 Becker DH, Townsend JJ, Kramer RA, et al. Occult cerebrovascular malformations. A series of 18 histologically verified cases with negative angiography. Brain 1979;102: 249-87.

49 Bartlett JE, Kishore-PR. Intracranial cavernous angioma. Am f Roentgenol 1977;128:653-6.

50 Matz P; McDermott M, Gutin P, et al. Cavernous malformations: results of image-guided resection. Fourne of Image Guided Surgery 1995;1:273-9.

51 Boecher-Schwarz HG, Grunert P, Guenthner M, et al. Stereotactically guided cavernous malformation surgery. Minim Invasisve Neurosurg 1996:39:50-5.

52 Bertalanffy H, Kuhn G, Scheremet R, et al. Indications for surgery and prognosis with cerebral cavernous angiomas. Neurol Med Chir 1992;32:659-66.

53 Acciarri N, Padovani R, Giulioni M, et al. Intracranial and orbital cavernous angiomas: a review of 74 surgical cases. Brf Neurosurg 1993;7:529-39.
54 Kitamura K, Fukui M, Oka K, et al. Hemangiomas of the central nervous system in Japan: an epidemiological and clinicopathological study with special reference to venous and cavernous malformations. Neurosurg Rev 1986;9:22131

55 Tiberin P, Beller AJ. Observations on so-called brain stones or cerebral calculi. Neurology 1899;464-76.

56 Pozzati E, Padovani R, Morrone B, et al. Cerebral cavernous angiomas in children. 7 Neurosurg 1980;53:826-32.

57 Porter P, Harper WD, Willinsky RA, et al. Cerebral cavernous malformations-natural history and prognosis after clinical deterioration with or without hemorrhage. 7 Neurosurg 1997;87:190-7.

58 Gomori JM, Grossman RI, Goldberg HI, et al. Occult cerebral vascular malformations: high-field MR images. Radiology 1986;158:707-13.

59 Vickrey BG, Hays RD, Engel JJ, et al. Outcome assessment for epilepsy surgery: the impact of measuring health-related quality of life. Ann Neurol 1995;37158-66.

60 Requena I, Arias M, Lopez Ibor L, et al. Cavernomas of the central nervous system: clinical and neuroimaging manifestations in 47 patients. I Neurol Neurosurg Psychiatry 1991;54:590-4.

61 Yeh H, Privitera MD. Secondary epileptogenesis in cerebral arteriovenous malformations. Arch Neurol 1997;48:1122-4.

62 Morell F. Secondary epileptogenesis in man. Arch Neurol 1985;42:318-35.

63 Cascino GD, Jack C, Parisi J, et al. Operative strategy in patients with MRI-identified dual pathology and temporal lobe epilepsy. Epilepsy Res 1993;14:175-82.

64 Symon L, Jackowski A, Bills D. Surgical treatment of pontomedullary cavernomas. Br f Neurosurg 1991;5:33947

65 McConnell TH, Leonard JS. Microangiomatous malformations with intraventricular hemorrhage. Report of two unusual cases. Neurology 1967;17:618-20.

66 Ondra SL, Doty JR, Mahla ME, et al. Surgical excision of a cavernous hemangioma of the rostral brain stem: case report. Neurosurgery 1988;23:490-3.

67 Hoeldtke NJ, Floyd D, Werschkul JD, et al. Intracranial cavernous angioama initially presenting in pregnany with new onset seizures. Am $\mathcal{F}$ Obstet Gynaecol 1988;178:612-3.

68 Kondziolka D, Lunsford LD, Flickinger JC, et al. Reduction of hemorrhage risk after stereotactic radiosurgery for cavernous malformations. F Neurosurg 1995;83:825-31.

69 Kida Y, Kobayashi T, Tanaka T. Treatment of symptomatic AOVMs with radiosurgery. Acta Neurochir Suppl (Wien) 1995;63:68-72.

70 Stea RA, Schiker L, King GA, et al. Strerotactic linear radiosurgery for cavernous angiomas. Stereotact Funct Neurosurg 1994;63:255-65.

71 Karlsson B, Kihlstrom L, Lindquist C, et al. Radiosurgery for cavernous malformations. $\mathcal{F}$ Neurosurg 1998;88:293-7.

72 Gewirtz RJ, Steinberg GK, Crowley R, et al. Pathological changes in surgically resected angiographically occult 42:738-42.

73 Seo Y, Fukuoka S, Takanashi M, et al. Gamma knife surgery for angiographically occult vascular malformations. Stereotact Funct Neurosurg 1995;64 (suppl 1):98-109.

74 Willmore LJ, Sypert GW, Munson JB. Recurrent seizures induced by cortical iron injection: a model of posttraumatic epilepsy. Ann Neurol 1978;43:29-36. 